\title{
Spatial Effect on Public Risk Perception of Natural Disaster: a Comparative Study in East Asia
}

\author{
Zhongyu He \\ Department of Urban Planning and Design, Nanjing University, 22 Hankou Road \\ Nanjing, Jiangsu 210093, China \\ E-mail: hezy@nju.edu.cn \\ Guofang Zhai \\ Department of Urban Planning and Design, Nanjing University, 22 Hankou Road \\ Nanjing, Jiangsu 210093, China \\ E-mail:Guofang_zhai@nju.edu.cn
}

Received 10 June 2015

Accepted 6 August 2015

\begin{abstract}
This paper explores the effect of geographical location on public risk perception of natural disasters. By conducting an identical questionnaire survey across three East Asia countries (China, Japan and South Korea), the paper finds out that different country has its unique structure of risk perception. Generally, the risk perception of sample residents in Japan weakens as the distance from the risk source increases, which indicates Japanese people's risk perception reflects the actual risk probability. On the other hand, Korean partially and Chinese hardly perceive the probability of existing risks. The findings of this paper imply that risk perception to certain extent relates with existing risk, however, the latter is not always correctly perceived. Economic development, socio-political system, historical and cultural backgrounds will affect public risk perceptions.
\end{abstract}

Keywords: spatial effect, risk perception, natural disaster, East Asia, closeness to risk

\section{Introduction}

Risk perception is defined as the personal belief that one can be potentially harmed or to be exposed to the risk. In a risk society claimed by Ulrich Beck (1986), the risk perception of the public plays an increasingly important role in shaping environmental policy and the risk management and response systems (Slovic, 2000). The beginning of risk perception research can be traced to the nuclear debate of the 1960s, yet today it still remains as a phenomenon in search of an explanation (Sjoberg, 2000). Of course, real risk is undoubtedly a primary factor that affects risk perception, as illustrated by some well sited papers (von Winterfeldt, John \& Borcherding, 1981; Lichtenstein et al., 1978). However, numerous empirical studies have reported that risk is perceived quite differently even in the case where the statistical probability of a certain risk is identical. Some scholars have examined the relationship between perceived risks and the type of disaster event and reported a significant result (Ho, Brossard \& Scheufele, 2008). Others tested how various individual-level characters like worldviews, education levels and religious preferences may influence attitudes and perceptions about risk issues and risk events (Kahann et al., 2006). On the other hand, a large body of literature focuses on how varied risk communication results in the disparity of risk perception under the cognitive-experiential theory or fuzzy trace theory (Epstein, 1994; Reyna \& Brainerd, 1991). Some specific discussion includes the framing effect (Tversky 
\& Kahneman, 1981), ratio bias (Yamagishi, 1997) and frequency effect (Slovic, Monahan \& MacGregor, 2000). Risk perception is also believed to be affected by risk target, namely, people do not make the same estimate when they rate the risk to themselves, to their family, or to people in general (Sjoberg, 2000).

Some recent studies have started to explore spatial issues related with risk perception. Teigen (2005) suggests that perceived closeness, whether physical or psychological, can influence perceptions of risk, while some others argue that psychological proximity to hazard has a greater influence (Brown et al., 1992). In another study, researchers find out that American citizens' risk judgment towards terrorist attack is positively correlated with their geographical distance to the World Trade Center (Fischhoff et al., 2003). Meanwhile, a spatial mismatch between real risks and perceived risks by the public is reported as well, for example, Brody et al. (2004)'s empirical study shows that people's perceptions of air quality in Texas, U.S.A. are not significantly correlated with scientifically measured pollution level in air monitoring stations. Therefore, as is pointed out, the spatial effect on environmental risk perception is still in lack of scientific and systematic study (Gattig \& Hendrickx, 2007).

\section{Geographical location and natural disaster perception}

Among the various environment, health and safety risks, natural disaster is the one whose risk probability is closely related with spatial location. For example, it is self-evident that the closer to a river, the more likely for a house to be suffered during a flood (Fig. 1), and similarly, residents who live near coastal areas have a bigger chance to be affected than those who live in the inner land during a Tsunami.

By conducting an identical questionnaire survey in three East Asia countries-Japan, China and South Korea, this paper aims to provide some explanation of the effect of geographical location on public risk perception towards natural disasters. To our best knowledge, it is the first international comparative research focusing on the spatial effect on risk perception and therefore will contribute to the quite limited studies on this topic. Especially, the following research questions are raised:

1) How does the risk perception of the public vary as the distance to natural disasters changes?

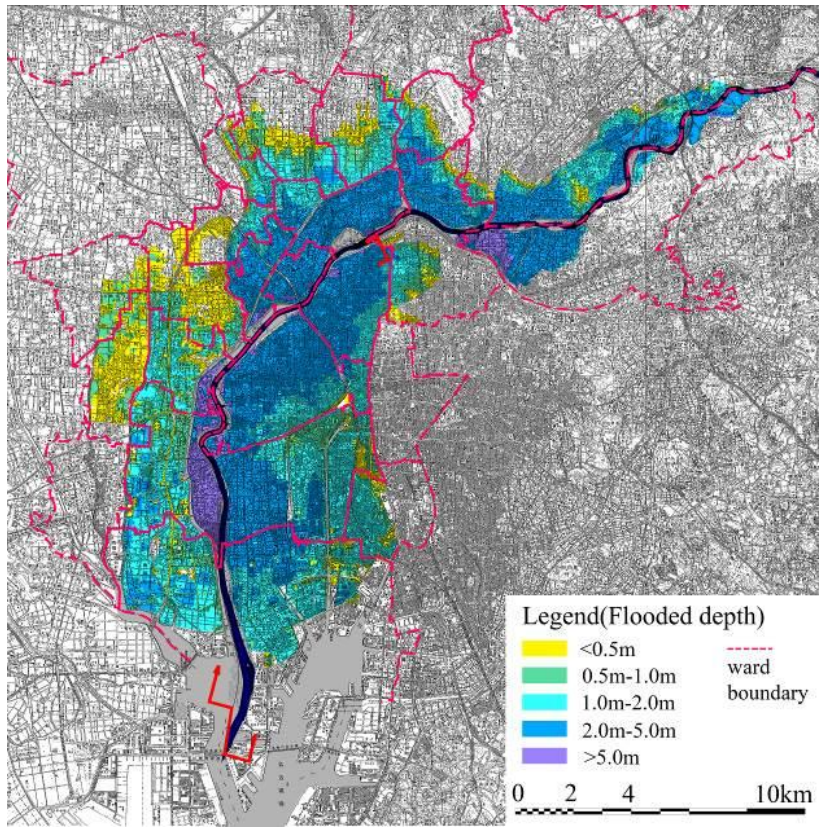

Fig. 1. Forecasted flooded area by Shonai River in Nagoya City, Japan (Source: Chubu construction bureau, MLIT, Japan, http://www.cbr.mlit.go.jp/shonai/sitemap/ 2015-06-01). This hazard map shows that the potential flooded depth of certain area is positively related with the proximity to the river.

2) Does the geographical location affects public risk perception in a similar or dissimilar way in the three countries?

3) What individual-level and country-specific factors account for the public risk perception?

Located in East Asia, the three target countries share some common historic backgrounds as they are all deeply influenced by the ancient Chinese civilization, at the same time they differ greatly in their economic development (Table 1.), social and political system as well as natural conditions.

Table 1. Main indicators in China, South Korea and Japan in the survey period (as of 2006)

\begin{tabular}{lccc}
\hline & China & Korea & Japan \\
\hline Area (100,000 km2) & 960 & 9.93 & 37.79 \\
Population (million) & 1316 & 48.3 & 127.8 \\
Nominal GDP (billion \$) & 2278 & 788 & 4554 \\
Nominal GDP Per Capita (\$) & 1732 & 16471 & 35650 \\
Real GDP growth rate (\%) & 10.2 & 4.0 & 3.1 \\
\hline
\end{tabular}




\section{Survey and Hypothesis}

The survey was carried out in 2006, around 3000 questionnaires were sent to residents living in three coastal cities with potential risk of Tsunami-Yokohama, Tianjin, Busan respectively. The initial questionnaire was designed in Japanese and then translated into Chinese and Korean by native speakers who are fluent in Japanese. The surveys were modeled after the Total Survey Design (TSD) method, which attempts to achieve an optimum balance across all areas of effort. In the end, 2278 questionnaires were returned with an average response rate of $73.7 \%$ (Table 2.).
As a comparison group, an earlier survey conducted in Japan's Nagoya city and Toki city in 2004 with a sample size of 428 is used together in the following analysis. The main difference between this survey and the cross-country one is that in the Nagoya-Toki survey, the target sample residents are living along the watershed of Shonai River in the inner land rather than coastal area, which indicates they face a potential risk of flooding rather than Tsunami.

For the purpose of this paper, 3 out of the 29 risks are selected for further analysis, namely Tsunami, flooding and global warming. Tsunami is a major threat to coastal residents while flooding is the most frequent

Table 2. Survey details

\begin{tabular}{|c|c|c|c|c|}
\hline & Japan_1 & Japan_2 & China & South Korea \\
\hline $\begin{array}{l}\text { Survey } \\
\text { time }\end{array}$ & $\begin{array}{c}\text { March } 24 \text { to April 16, } \\
2004\end{array}$ & $\begin{array}{l}\text { April } 14 \text { to May } 14, \\
2006\end{array}$ & $\begin{array}{l}\text { Mid. Nov. to Mid. Dec., } \\
2006\end{array}$ & Nov.1 to Dec. 11,2006 \\
\hline $\begin{array}{c}\text { Focused } \\
\text { participants }\end{array}$ & Watershed residents & Coastal residents & Coastal residents & Coastal residents \\
\hline $\begin{array}{l}\text { Sampling } \\
\text { method }\end{array}$ & $\begin{array}{l}\text { Random sampling from } \\
\text { telephone directory }\end{array}$ & $\begin{array}{l}\text { Random sampling from } \\
\text { telephone directory }\end{array}$ & $\begin{array}{l}\text { Random sampling from } \\
\text { school list }\end{array}$ & On-site delivery \\
\hline $\begin{array}{l}\text { Distributed } \\
\text { samples }\end{array}$ & 1000 & 1000 & 1000 & 1090 \\
\hline $\begin{array}{l}\text { Validly } \\
\text { samples }\end{array}$ & 962 & 835 & 1000 & 1090 \\
\hline $\begin{array}{l}\text { Returned } \\
\text { samples }\end{array}$ & 428 & 450 & 963 & 865 \\
\hline $\begin{array}{l}\text { Survey } \\
\text { process }\end{array}$ & $\begin{array}{l}\text { Delivering survey } \\
\text { booklets to sampled } \\
\text { participants along with } \\
\text { reply postcards } \\
\text { Sending reminder } \\
\text { postcards to remind } \\
\text { returning the reply } \\
\text { postcards } \\
\text { Collecting the booklets }\end{array}$ & $\begin{array}{l}\text { Delivering survey } \\
\text { booklets to sampled } \\
\text { participants along with } \\
\text { reply postcards } \\
\text { Sending reminder } \\
\text { postcards to remind } \\
\text { returning the reply } \\
\text { postcards } \\
\text { Collecting the booklets }\end{array}$ & $\begin{array}{l}\text { Delivering survey } \\
\text { booklets to sampled } \\
\text { schools } \\
\text { Sampled schools } \\
\text { distributed booklets to } \\
\text { students } \\
\text { Students took booklets } \\
\text { back and their parents } \\
\text { answered them. } \\
\text { Collecting the booklets }\end{array}$ & $\begin{array}{l}\text { Delivering the survey } \\
\text { booklets to surveyors. } \\
\text { Surveyors distributed } \\
\text { booklets to participants. } \\
\text { Collecting the booklets }\end{array}$ \\
\hline
\end{tabular}

Risk perception was measured through the survey by asking the question: "Using a scale from 0 to 10 where 0 is the least and 10 is the most, how strongly do you feel about the following risks?" Then 29 daily risks including natural disasters, epidemic diseases and incidents appeared in the questionnaire. Individual characters of the respondent such as sex, age, income and education level are recorded. The respondents were also asked to provide the direct distance from their home to the coast line. natural disaster occurred in watershed areas; the risk of both disasters decreases as the distance to coast line or river bank increases. On the other hand, global warming is a universal natural disaster producing damages to all the human beings with no regard to geographical locations.

Therefore, suppose people make rational decisions, the following hypothesis can be made:

Hypothesis 1: If the risk of global warming is correctly perceived, then people's risk perception 
should bear no relationship with their spatial location from coast line or river bank.

Hypothesis 2: If the risk of Tsunami is correctly perceived, then for residents living in coastal areas, their risk perception will decrease as they live further away from coast line while for residents living in watershed areas, their risk perception should bear no relationship with their residence location.

Hypothesis 3: If the risk of flooding is correctly perceived, then for residents living in watershed areas, their risk perception will decrease as they stay further away from river bank while for residents living in coastal areas, their risk perception should bear no relationship with their residence location.

Section 4 and section 5 will examine if these hypothesis can be validated or not.

\section{Three tests of spatial effect on risk perceptions}

Test 1: First, the relationship between the public risk perception towards global warming and distance from coast line in the three countries are examined. The distance is divided into 6 groups: those who live less than $100 \mathrm{~m}$ from the coast line, between $100 \mathrm{~m}$ and $500 \mathrm{~m}$, between $500 \mathrm{~m}$ and $1 \mathrm{~km}$, between $1 \mathrm{~km}$ and $2 \mathrm{~km}$, between $2 \mathrm{~km}$ and $5 \mathrm{~km}$, and those who live further than $5 \mathrm{~km}$ from the coast line. Respondents who state they are not sure about the distance are excluded from the analysis; this is why the number of observations is less

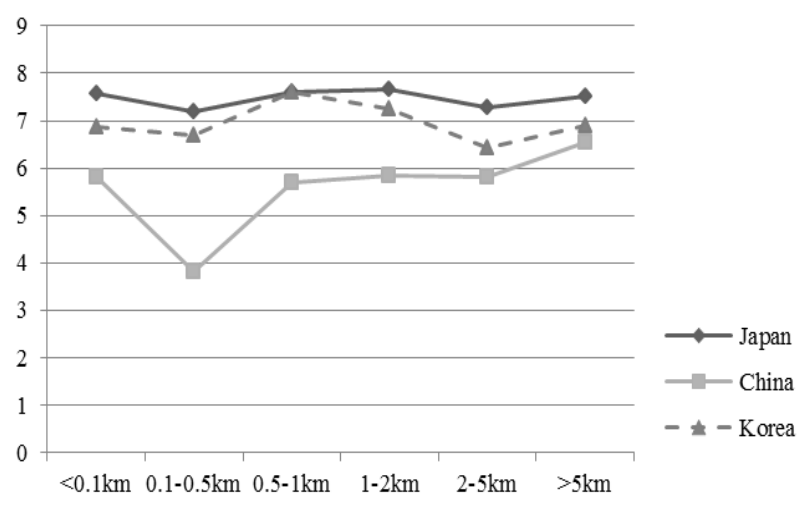

Fig. 2. Global warming risk perception with regard to distance from coast line (No. of observations: Japan $=395$, China $=535$, Korea $=658$ ) than the number of total valid samples. As Fig. 2 shows, Japanese have the strongest risk perception in the three countries, and Koreans' risk perception is stronger than that of Chinese respondents'.

The perceived risks are not related with geographical locations in all the three groups, thus Hypothesis 1 cannot be denied. However, we are not sure if this result is due to correct risk perception or merely a coincidence. Therefore, it is necessary to do some further test.

Test 2: In the next step, a similar examination about Tsunami risk is carried out (Fig. 3), and an interesting pattern is found out: basically, Japanese respondents correctly judge the real risks because their risk perception score lowers as the distance from coast line increases, and an F-test shows that the difference between different distance groups is statistically significant ( $\mathrm{p}$-value $=0.001$ ). The risk perception of Korean respondents' is partially correct, for a general decreasing tendency can be observed. On the other hand, the risk perception of the Chinese respondents' can hardly reflect existing risk in reality. The result indicates that for Chinese and Korean group, the observation in Test 1 is a coincidence, and as a matter of fact, neither of the Hypothesis 1 and Hypothesis 2 should be accepted. However, for the Japanese group, the two hypotheses seem to be true. To confirm the conclusion, another test is done as follows.

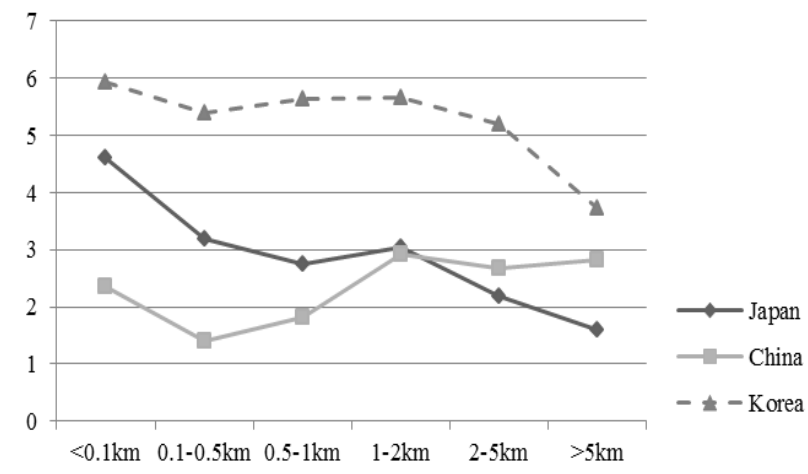

Fig. 3. Tsunami risk perception with regard to distance from coast line (No. of observations: Japan $=395$, China $=538$, Korea $=658$ ) 
Test 3: In this final test, we compare the two Japanese groups (one from coastal area and the other from watershed area) and check how the three risks (global warming, Tsunami and flooding) are perceived in the two groups. As shown in Fig. 4 and Fig. 5, the score of global warming shows no relationship with distance from coast line or river bank in both groups. For the coastal area group, the score of Tsunami risk has

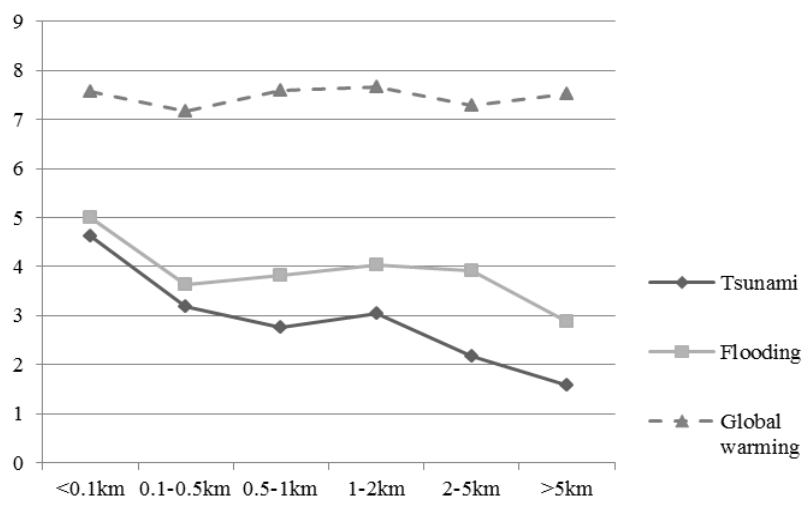

Fig. 4. Risk perception of the Japanese coastal area group (No. of observations: Tsunami=395, Flooding=395, Global warming $=395$ )

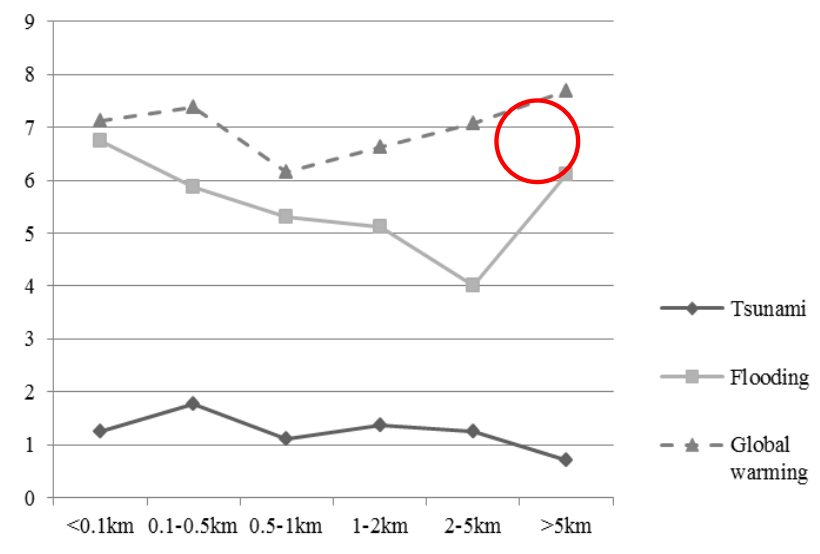

Fig. 5. Risk perception of the Japanese watershed area group (No. of observations: Tsunami=339, Flooding=351, Global warming $=353$ ).

an obvious positive correlation with proximity to coast line (sig. $=0.001$ in F-test) while the score of flooding indicates a disconnection between distance and risk perception (sig. $=0.074$ in F-test). At the same time, for the watershed area group, an opposite pattern is found out ( $\mathrm{p}$-values in F-tests checking difference between different distance groups are 0.508 for Tsunami and
0.000 for flooding), expect the last group that lives more than $5 \mathrm{~km}$ away from river bank (as the red circle shows in Fig. 5). A further look upon this group reveals that the number of samples in this group is merely 10; therefore, it is reasonable to attribute the unexpected score of this group to the inadequate sample size. If this last group is dropped out, then the flooding risk perception will present a perfect pattern that goes down with the distance from home to the river bank increases. The results in Test 3 are totally in line with the three hypotheses made earlier. So far, it is quite convincing to reach the conclusion that geographical location affects Japanese people's risk perception towards natural disaster in a dramatic way and in other words, Japanese people always perceive natural disasters in a more sensitive and correct way than South Korean and Chinese people.

\section{Regression Analysis}

Analysis in Section 4 reveals an interesting finding and confirms some of the concern of the paper. To fully understand factors that impact public risk perception, especially the separated influence from individual-level characteristics and spatial effect in different countries, a multivariate regression analysis is done in SPSS.

Three models are established, and the regression result is shown in Table 3, the dependent variable is the score of perceived risk towards Tsunami, and it is dealt as a consecutive variable ranging from 0 to 10 . Independent variables include age, gender, family's annual income, education level of the respondent, and distance from home to coast line. Age is divided into 7 groups with an interval of 10 years. Family's annual income is set based on the actual income level in each country and is treated as a consecutive variable with higher value indicating a higher income. For distance, again those who answered they were not sure about the distances from their home to the coast line are excluded from the regression.

Generally speaking, adjusted R2 of all the three models are quite small and therefore the goodness of fit of the models are not satisfying, which implies that individual characteristics and spatial location are not major factors that affect risk perception. Sex and education level in all three countries are not statistically related with Tsunami risk perceptions. Age and income have no impact on risk perception for Chinese and Japanese respondents, neither. However, for 
respondents from South Korea, older people and people with higher income show a stronger feeling about potential Tsunami hazard. As for the spatial effect, the
$(<0.1 \mathrm{~m}$ and $>5 \mathrm{~km})$. For the survey in China, no pattern can be observed. The direction of the spatial variables is not identical, and none of the variables are significant.

Table 3. Regression results

\begin{tabular}{|c|c|c|c|}
\hline Independent variable & Japan & China & South Korea \\
\hline Sex $($ Male $=0$, Female $=1)$ & .013 & -.049 & -.040 \\
\hline $\begin{array}{c}\text { Age }(1=10-19 \text { years old, } 2=20- \\
29 \text { years old, } \ldots, 7=\text { older than } 70 \\
\text { years })\end{array}$ & -.133 & .002 & $.499 * * *$ \\
\hline Family annual income & .027 & .012 & $.119 * * *$ \\
\hline \multicolumn{4}{|l|}{ Education (Ref.=Middle school) } \\
\hline $\begin{array}{l}\text { High school } \\
\text { Vocational school } \\
\text { College } \\
\text { Postgraduate }\end{array}$ & $\begin{array}{l}-.385 \\
-.017 \\
-.606 \\
-.806\end{array}$ & $\begin{array}{l}-.368 \\
-.905^{* *} \\
.046 \\
-1.342\end{array}$ & $\begin{array}{c}1.410 \\
2.133^{* *} \\
.834 \\
1.369\end{array}$ \\
\hline \multicolumn{4}{|l|}{ Distance $($ Ref. $=<0.1 \mathrm{~km})$} \\
\hline $\begin{array}{c}0.1-0.5 \mathrm{~km} \\
0.5-1 \mathrm{~km} \\
1-2 \mathrm{~km} \\
2-5 \mathrm{~km} \\
>5 \mathrm{~km}\end{array}$ & $\begin{array}{c}-1.242 * \\
-1.630^{* *} \\
-1.337 * \\
-2.220^{* * *} \\
-3.175^{* * *}\end{array}$ & $\begin{array}{c}-.538 \\
-.521 \\
1.043 \\
.354 \\
.678\end{array}$ & $\begin{array}{c}-.843 \\
-.842 \\
-1.037 \\
-1.179 \\
-2.388 * *\end{array}$ \\
\hline Constant & $5.536^{* * *}$ & $2.484 * * *$ & $2.970^{* *}$ \\
\hline $\begin{array}{l}\text { No. of observations } \\
\text { Adjusted } \mathrm{R}^{2}\end{array}$ & $\begin{array}{c}395 \\
0.019\end{array}$ & $\begin{array}{l}538 \\
0.005\end{array}$ & $\begin{array}{l}658 \\
0.140\end{array}$ \\
\hline
\end{tabular}

$* * *$ p-value $<0.01 * *$ p-value $<0.05 *$ p-value $<0.1$

regression results confirm the above conclusions from Section 4: for the survey in Japan, all the spatial variables are significant in the model.

For example, compare with residents living within $100 \mathrm{~m}$ from the coast line, those living at a distance of $100 \mathrm{~m}$ to $500 \mathrm{~m}$ from coast line will have a lower score of about 1.2 in their feeling about potential risk of Tsunami, and those living more than $5 \mathrm{~km}$ from the coast line will have a lower score of about 3.2. For the survey in South Korea, only the last spatial variable is statistically significant, even though the directions of all the other spatial variables are negative (-) in the model. This indicates that South Korean residents living further from coast line tend to think the Tsunami risk is lower than those living closer from coast line; however, they are not as sensitive as their Japanese counterparts, the risk perceptions are statistically different only when the disparity of proximity to coast lines is large enough

\section{Discussion and Conclusion}

By conducting an identical questionnaire survey across three East Asia countries (China, Japan and South Korea) with a sample size of more than 2,200, this paper investigate the spatial effect on public risk perception towards natural disaster. A second concern of the paper is how individual characters influence the risk judgment The relationship between geographic location and risk perception is a rarely discussed topic in existing literature; the comparative study between the three countries shows that different country has different structures of risk perception. And generally speaking, Japanese basically, South Koreans partially and Chinese hardly perceive the existence of real risks. For natural disasters whose influence is identical across space (e.g. global warming), Japanese people's risk perception is not related with their geographical location; while for 
natural disasters whose risk is closely related with proximity to the risk source (e.g. flooding, Tsunami), Japanese people's risk perception is weakened as their distance from the risk source increases. This finding supports previous research (Sjoberg, 2000; von Winterfeldt, John \& Borcherding, 1981; Lichtenstein et al., 1978) that real risk does affect risk perception, however, the mixed results from the three countries imply that real risks are not always correctly perceived, this is also confirmed by other papers (Brody, Peck \& Highfield, 2004). Some reasons may account for this difference in the capability of risk judgment:

First, based on the results of this paper, a country's economic development is one factor that correlates with public risk perception, even though it is not necessarily to be a causal relationship. According to the Hierarchy of Needs Theory by Maslow, physiological needs is the most fundamental level of needs for human beings; safety needs is on a higher hierarchy and only with people's physical needs relatively satisfied, does the individual's safety needs take precedence and dominate behavior. In a less developed economy, its citizens will consider more about physical requirements for human survival like food, clothing, shelter, etc. while the more developed an economy is, the more likely physiological needs will be satisfied and therefore in a developed economy, people will concern more on safety issues like the potential risks of natural disasters. This may explain the different levels of risk judging performances in China-a developing country, South Korea-a new industrialized country and Japan-a highly developed country.

Second, socio-political system also exerts an impact on public risk perception. Previous literature has found that trust in government can influence people's perceptions and reactions to issues of food safety (Houghton et al., 2006; Kuttschreuter, 2006), and this seems be true for natural disasters too. Japan is well known for its well-designed risk management system and legislation; Japanese government is also among the top countries in Government transparency ranking. Both the central and local governments in Japan have been making great efforts in risk education and risk communication with the public. These measures largely improve the public understanding towards natural disasters and help the public build a correct perception towards these risks. On the other hand, Korean and Chinese governments still have some space to improve in their emergency management and risk information disclosure. The result in Japan's survey not only implies that our respondents have a clear risk judgment, but also indicates they have an identical judging criterion. And this cannot be achieved without the effective risk education from the government.

Third, historic and cultural backgrounds will influence risk perception in one society as well. Due to its special geographical location, Japan has been suffering from the most disadvantageous natural conditions in the world. Frequently occurred disasters have shaped the country's unique cultural character, namely a crisis consciousness embedded in daily behavior (Gao, 2003). As a result, Japanese people are always prepared to various natural disasters and show more interests in accessing risk information. We believe such a personal concern will lead to a better risk understanding and to some extent explain the better performance of the Japanese respondents in the survey.

Existing literature has pointed out that personal disaster experience also affects individual's risk perception. However, since no Tsunami has occurred in the three sample cities in recent history, the factor of personal experience can be excluded in explaining the difference in risk perceptions in the three countries.

This paper also finds out that individual level characters, especially demographic factors, are not closely related with risk perception. This is not difficult to understand, for risk perception is a highly subjective judgment and may not be affected by a person's physical condition such as income or education. Besides, existing literature argues that demographic factors have different powers in explaining risk perception towards different hazard events (Cummings, Berube \& Lavelle, 2013). For example, education level is statistically significant for perceived emerging technological risks but not for manufacturing risks (Cummings, Berube \& Lavelle, 2013). Meanwhile, some studies show that some other individual characters like worldview, religious belief, ideology and political identification significantly affect risk perception (Brody, Peck and Highfield, 2004; Cummings, erube \& Lavelle, 2013). Since all these factors belong to the psychological dimension as same as risk perception, their findings are quite reasonable. Also, these papers reveal that preferred media for information seeking somewhat accounts for public risk perception; due to the limited 
space in the questionnaire, this factor is not tested in our survey.

Risk geography is a relatively new branch in geography discipline. To help the public establish a correct risk perception with regard to space and location is quite important in a society with increasing uncertainty and hazard, since risk perception is closely related with the public's response to the risk, and therefore determine whether the social and economic resource will be allocated effectively. When there is a mismatch between the real risk and perceived risk, the value of land and space will be distorted and economic loss will occur for the whole society. The current paper is a preliminary study to explore the spatial aspects of risk perception, future study can further examine if the explanations provided in this paper can be validated by conducting more elaborate experiments. Future research can also thoroughly check the influence of culture by doing comparative studies between the western and eastern countries. What is more, it is important for policy makers to find out how to improve the public's spatial consciousness towards natural disaster risks through effective risk communications.

\section{Acknowledgements}

This research was co-supported by the National Program on Key Basic Research Project of China (973) under grant No. 2010CB428506 and Project of National Natural Science Foundation of China under grant No. 51308280

\section{References}

U. Beck, Risk Society: Towards a New Modernity (Sage, New Deli, 1986)

P. Slovic, Perception of risk. in The Perceptions of Risk, eds. P. Slovic (EarthScan Publications, London, 2000), pp. 220231.

L. Sjoberg, Factors in risk perception, Risk Analysis. 20(1) (2000) 1-11.

D. von Winterfeldt, R. S. John, and K. Borcherding, Cognitive Components of Risk Ratings, Risk Analysis 1(2) (1981) 277-287.

S. Lichtenstein et al., Judged Frequency of Lethal Events, Journal of Experimental Psychology: Human Learning and Memory 4 (1978) 551-578.

S. Ho, D. Brossard, and D. Scheufele. Effects of Value Predispositions, Mass Media Use, and Knowledge on Public Attitudes: Toward Embryonic Stem Cell Research, International Journal on Public Opinion Research 20 (2) (2008) 171-192.
D. Kahan, P. Slovic, D. Braman, and J. Gastil, Fear of Democracy: A Cultural Evaluation of Sunstein on Risk, Harvard Law Review 119 (2006) 1071-1109.

S. Epstein, Integration of the cognitive and psychodynamic unconscious, American Psychologist 49 (1994) 709-724.

V.F. Reyna and C.J. Brainerd, Fuzzy-trace theory and framing effects in choice, Gist extraction, truncation, and conversion, Journal of Behavioral Decision Making 4 (1991) 249-26.

A. Tversky and D. Kahneman, The framing of decisions and the psychology of choice, Science 211 (1981) 453-458.

$\mathrm{K}$. Yamagishi, When a $12.86 \%$ mortality is more dangerous than 24.14\%: Implications for risk communication, Applied Cognitive Psychology 11 (1997) 495-506.

P. Slovic, J. Monahan and D.G. MacGregor, Violence risk assessment and risk communication: The effects of using actual cases, providing instructions, and employing probability vs. frequency formats, Law and Human Behavior 24 (2000) 271-296.

K.H. Teigen, The proximity heuristic in judgments of accident probabilities, British Journal of Psychology 96 (2005) 423-440.

J. D. Brown, N. J. Novick, K. A. Lord, and J. M. Richards, When Gulliver travels: Social context, psychological closeness, and self-appraisals, Journal of Personality and Social Psychology 62 (1992) 717-727.

B. Fischhoff, R. M. Gonzalez, D. A. Small and J. S. Lerner, Judged terror risk and proximity to the World Trade Center, Journal of Risk and Uncertainty 26 (2003) 137-151.

S.D. Brody, B.M. Peck and W.E. Highfield, Examing localized patterns of air quality perception in Texas: A spatial and statistical analysis. Risk Analysis 24 (6) (2004) 1561-1574

A. Gattig and L. Hendrickx, Judgmental discounting and environmental risk perception: Dimensional similarities, domain differences, and implications for sustainability. Journal of Social Issues 63 (1) (2007) 21-39

J. R. Houghton, E. van Kleef, G. Rowe and L. J. Frewer, Consumer perceptions of food risk management practices: A cross-cultural study. Health, Risk and Society 8 (2) (2006) 165-183.

M. Kuttschreuter, Psychological determinants of reactions to food risk messages. Risk Analysis 26 (4) (2006) 1045-1057.

F. Gao, Consciousness of crisis and characteristics of Japanese culture, Japanese Study Forum 1 (2003) 30-33. (in Chinese)

C. L. Cummings, D. M. Berube and M. E. Lavelle, Influences of individual-level characteristics on risk perceptions to various categories of environmental health and safety risks, Journal of Risk Research, 16 (10) (2013) 1277-1295. 